\title{
Women's perceptions of being pregnant and having pregestational diabetes
} \author{
(Consultant Midwife) $^{\mathrm{e}}$, Lisa Baker, MPhil, RM (Midwifery Research Co-ordinator) \\ a University of Manchester, School of Nursing, Midwifery and Social Work, Oxford Road, Manchester M13 9PL, UK \\ b University of Liverpool, UK \\ ${ }^{\mathrm{c}}$ University of Central Lancashire, UK \\ d Aintree University Hospital NHS Foundation Trust, UK \\ e East Lancashire Hospitals NHS Trust/University of Central Lancashire, UK \\ ${ }^{\mathrm{f}}$ Liverpool Women's Foundation Trust, UK
}

Tina Lavender, PhD, MSc, RM (Professor of Midwifery) ${ }^{\mathrm{a}, *}$, Mary Jane Platt, MBBS, MPH, MD [Deputy Director of Medical Studies and Senior Lecturer (Clinical) Public Health Medicine] ${ }^{\mathrm{b}}$, Ediri Tsekiri, BSc (Hons) (Research Assistant) ${ }^{\mathrm{c}}$, Ian Casson, MD, FRCP, MB.Ch.B ${ }^{\mathrm{d}}$, Sheena Byrom, MA, RM Stephen Walkinshaw, FRCOG, MRCOG, MD (Consultant in Fetal and Maternal Medicine) ${ }^{\mathrm{f}}$

\section{A R T I C L E I N F O}

\section{Article history:}

Received 19 September 2008

Received in revised form

8 January 2009

Accepted 11 January 2009

Keywords:

Diabetes

Pregnancy

Phenomenology

Qualitative

\begin{abstract}
A B S T R A $\mathrm{T}$
Objective: to explore the experiences of White British and South East Asian women with type 1 and type 2 diabetes, and the perceived impact of diabetes on their reproductive health.

Design: a hermeneutic phenomenological approach was used to explore the perceptions of women with diabetes from two different cultural backgrounds with varied reproductive health experiences. Focus groups and one-to-one interviews were used to elicit women's experiences. An interpretive analytical approach was conducted by two researchers.

Setting: obstetric and diabetes clinics in three hospital sites in the North West of England.

Participants: a purposive sample of 22 women with type 1 or type 2 diabetes of different parity and ethnicity.

Findings: the main themes were relinquishing personal control, pregnancy overshadowed by diabetes and haphazard preconception care.

Key conclusions: strategies should be developed to ensure that whilst safety is maintained, the pregnancy focus is not lost. Women should be supported to optimise their experience as well as clinical outcomes. The convergence of professional roles needs consideration; individual members of multidisciplinary diabetes teams should provide a unique and complementary contribution to care. Preconception care needs to be accessible and responsive to women; this should include recognition of socio-cultural differences.
\end{abstract}

(c) 2009 Elsevier Ltd. All rights reserved.

\section{Introduction}

Diabetes mellitus is one of the most common pre-existing medical conditions complicating pregnancy (Confidential Enquiry into Maternal and Child Health, 2007). The St Vincent Declaration's (Workshop Report, 1990) target that the outcomes of pregnancy in women with diabetes should approximate those of women without diabetes has not yet been reached; this is despite improvements in obstetric and neonatal care and diabetes management. Pregnancy in women with pregestational diabetes has been shown to be associated with adverse outcomes for both mother and fetus, with higher rates of labour induction

\footnotetext{
* Corresponding author.

E-mail address: tina.lavender@manchester.ac.uk (T. Lavender).
}

(Landon, 1987; Nielsen and Nielsen, 1993; McAuliffe et al., 1999; Williams and Pickup, 2004), operative and premature childbirth in the mother (Nielsen and Nielsen, 1993; Hanson and Persson, 1993; Hawthorne et al., 1997; Evers et al., 2004) and five times higher rates of stillbirth, neonatal mortality and congenital anomalies in the offspring (Hawthorne et al., 1997; Casson et al., 1997; Hadden et al., 2001; Platt et al., 2002; Macintosh et al., 2006).

Although preconception care reduces congenital malformation in the babies of mothers with diabetes, most women do not discuss preconception care with diabetes health professionals when planning their pregnancies (Hawthorne, 2005; Confidential Enquiry into Maternal and Child Health, 2007). Ideally, all women with diabetes should plan their pregnancies with advice from their diabetes care team, as there is a strong evidence to show that such care can alter behavioural, medical and other health risk 
factors known to influence pregnancy outcomes (Curtis et al., 2006). In reality, however, a recent survey showed that over half of women with pregestational diabetes mellitus are poorly prepared for pregnancy (Confidential Enquiry into Maternal and Child Health, 2007). In this survey, less than half of women with diabetes were taking folic acid prior to conception, less than half received preconception counselling, and only one-third were recorded to have a test of glycaemic control in the six months prior to pregnancy. Furthermore, two-thirds of women are reported to have evidence of sub-optimal glycaemic control before conception and in the first trimester of pregnancy (Confidential Enquiry into Maternal and Child Health, 2005).

Although there is a plethora of literature reporting outcome data related to diabetes management in pregnant women (Kapoor et al., 2007), few qualitative studies have explored, in-depth, the issues around reproductive health and diabetes from the woman's perspective. Pregnant women considered to be 'high risk' are more vulnerable (Berg et al., 2003) and more anxious (Hatmaker and Kemp, 1998; Gupton et al., 2001) than those with normal risk status. One of the few qualitative studies exploring pregnancy and diabetes describes the woman as having a 'high risk' body which, for the unborn child's sake, is controlled by blood glucose levels (Berg and Honkasalo, 2000). A further study of 18 women with type 1 diabetes, by the same author, proposes a phenomenon summarised as 'to master or to be enslaved', highlighting the internal emotional battle for women of wanting to protect their child whilst remaining in control of their own experience (Berg, 2005). This analogy is an interesting way of illuminating the co-existence of negative and positive feelings felt by women. These Swedish studies offer important insight into women's perspectives; however, global and cultural variations in health-care practice limit their transferability.

Evidence to inform strategies that are likely to improve the maternity services offered to women with diabetes remains limited. Consequently, the diabetes community does not know which interventions are both effective and acceptable to women, and so could result in improvements in outcome. Multifaceted interventions that consider the complexities of women's beliefs, behaviour and social environment may be required to improve outcomes and the pregnancy experience. It may be unacceptable, for example, to developing a drop-in service for women with diabetes if consideration has not been given to the content of the session or the acceptability of its format to women of different socio-cultural groups. Furthermore, it may be that different options are needed to allow flexibility for individual needs. It is therefore imperative that a greater understanding of women's views is sought in order to target such interventions appropriately. It is only when research explores the perceptions of women living with diabetes that clinicians can begin to appreciate the challenges that these women face, and thus practice more effectively and empathetically. This study has therefore provided a key starting point in bridging the gap in current knowledge, having generated a greater understanding of issues relevant to women with diabetes in relation to their reproductive health.

\section{Research design and methods}

A hermeneutic phenomenological approach was used to explore the perceptions of women with diabetes from two different cultural backgrounds, namely White British and South East Asian, who had varied reproductive health experiences. Phenomenology aims to develop insights from the perspectives of those involved in a particular 'lived experience,' a term that is synonymous with this approach (Mapp, 2008). An interpretive phenomenological approach, i.e. hermeneutics, was used based on the philosophy of Heidegger (1962). This approach emphasises the centrality of the participants in exploring the meanings of the phenomena.

Ethical approval was received by the local research ethics committee.

\section{Sample and setting}

A purposive sample of pregnant and non-pregnant women was obtained from those attending specialist diabetes clinics in two areas in the North West of England. Purposive sampling is appropriate when using a phenomenological approach due to the importance of selecting individuals who have knowledge of the phenomena concerned (Clifford, 1997). The sample was to include pregnant and non-pregnant women of different parity, ethnicity (White British and South East Asian) and diabetes type.

The first study area offers care for pregnant and non-pregnant women with diabetes and serves two local ethnic minority populations, Pakistani and Indian. Of 3400 births per annum, $36 \%$ of women are of South East Asian heritage. South East Asian consumers from this unit were trained as lay researchers and played a pivotal role in this research, assisting with recruitment, obtaining consent, facilitating interviews, transcription and translation.

In the second study area, non-pregnant women of childbearing age were recruited from a unit which offers a multidisciplinary outpatient diabetes service. Pregnant women were recruited from a different unit within the same area. These sites have a relatively low ethnic minority rate $(<11 \%)$, and the population varies in terms of socio-demographic details.

\section{Recruitment}

Pregnant women with type 1 and type 2 diabetes were identified from clinic lists and information sheets were provided. Opportunity was given to discuss the study and, at a subsequent clinical visit, written consent was obtained.

The non-pregnant cohort attended clinic less frequently, usually once every six months. Therefore, women were identified from consultants' clinic lists and information sheets were posted. Women were given time to consider participation and contacted to ascertain their decision and make arrangements for interviews. A choice of individual or focus group interviews was offered and these were arranged at mutually convenient times.

\section{Data collection}

Baseline data were collected on a brief questionnaire, prior to interview. Information sought included age, year diagnosed with diabetes, frequency of self-testing, diabetes management (i.e. diet, tablets, insulin), additional significant health problems, number of hospital admissions in the last five years and whether these were diabetes related or reproductive health related.

A semi-structured interview schedule was used to enable exploration of the broad areas of interest, whilst encouraging respondent-led inquiry. Individual interviews took place either in a private room in the hospital or in the participant's own home, according to individual choice. Focus groups took place in the hospital. In keeping with the Heidergerrian phenomenological approach (Heidegger, 1962), the interviewer did not 'bracket' her own preconceived ideas of diabetes. 


\section{Analysis}

Interviews were audio recorded and transcribed verbatim, using pseudonyms to protect identity. Interviews conducted in Punjabi and Urdu were transcribed and translated by the lay researcher. Back translation was also conducted, i.e. the quality of the translations was verified by an independent translator translating back into the original language.

The data were managed manually, i.e. without the aid of a software package. The interpretive process was guided by the principles of the philosophers Heidegger (1962) and Gadamer (1989). The aim of interpretive inquiry is to identify common themes across the participants that form a pattern of understanding. The objective is to reveal and articulate the essence of the lived experience. To meet this objective, it was crucial to search for the commonality as well as diversity of participants' experiences. This involved immersion in the data by reading and re-reading each interview in a search for emerging themes. Individual segments of texts were considered in relation to the overall interview, and each sentence was assessed for the meaning of the phenomena (Carter, 2004). This was a cyclical process whereby the researchers moved back and forth between the whole text and segments of the text to gain some understanding of the phenomena being explored.

In the first instance, two researchers (TL and ET) carried out simultaneous analysis. Collaborative reflective discussions, as described by Van Manen (2002), then took place with the whole research team to generate deeper insights and understandings. Given that members of the team worked within the field of study, this enabled them to share their views of the way the description did or did not resonate with their own experiences. Themes were then examined, articulated, re-interpreted and reformulated.

\section{Findings}

Of 49 women who received the information sheet, 22 women consented to take part in the study and were interviewed; 20 individual interviews and two focus groups were carried out ( $n=3, n=2$ ). Three women attended twice, at their request (two attended both focus groups; one had an individual interview and attended the second focus group).
Participant profiles are shown in Table 1.

Although African women were not part of the original eligibility criteria, an information sheet was sent to one woman in error. Given that this study was exploratory and this woman was keen to participate, she was included in the study.

All but one of the women managed their diabetes with insulin. The median number of times that women self-monitored their glucose levels each day was four (range two to 10) daily. For the non-pregnant sample, the median number of times was three (range two to four), and for the pregnant sample, the median number of times was four (range four to 10).

Most women had no other significant health problems $(n=13)$. Those that did, reported under- or overactive thyroid $(n=4)$, high blood pressure $(n=2)$, background retinopathy $(n=1)$, poor eyesight $(n=1)$ and thalassaemia $(n=1)$. The total number of hospital admissions reported by the women in the last five years ranged from zero to six, with a median of one admission. Of the women who had been admitted to hospital, six indicated that their admissions had been diabetes related and six were reproductive health related.

\section{Main themes}

Three main themes contribute to the lived experience of the participants: relinquishing personal control, pregnancy overshadowed by diabetes and haphazard preconception care. Although presented separately, these themes are inter-related. The pregnant and non-pregnant women had similar views on pregnancy and diabetes, with the exception of 'disruption to everyday lives'; a sub-theme of relinquishing personal control. Unsurprisingly, nonpregnant women had less disruption. Similarities were identified between ethnicity, parity and diabetes type. Where differences were identified, these are highlighted in the text.

\section{Relinquishing personal control}

Personal childbirth control has been reported as central to a positive experience (Lavender et al., 1999; Gibbins and Thomson, 2001). However, in this study, most women commented on the

Table 1

Participant profiles.

\begin{tabular}{|c|c|c|c|c|c|c|c|}
\hline Participants $^{\mathrm{a}}$ & Gravida & Parity & Ethnicity & Pregnancy state & Age (years) & Diabetes type & Duration of diabetes (years) \\
\hline Carol & 0 & 0 & White & Non-pregnant & 39 & 1 & 26 \\
\hline Joanna & 0 & 0 & White & Non-pregnant & 26 & 2 & 8 \\
\hline Karen & 3 & 1 & White & Non-pregnant & 39 & 1 & 4 \\
\hline Anne & 1 & 1 & White & Non-pregnant & 34 & 2 & 3 \\
\hline Paula & 1 & 1 & White & Non-pregnant & 32 & 1 & 21 \\
\hline Gill & 0 & 0 & White & Non-pregnant & 31 & 1 & 19 \\
\hline Yana & 0 & 0 & SE Asian & Non-pregnant & 27 & 1 & 16 \\
\hline Shilpa & 1 & 1 & SE Asian & Non-pregnant & 32 & 2 & 5 \\
\hline Heather & 1 & 0 & White & Pregnant & 27 & 1 & 23 \\
\hline Samantha & 3 & 0 & White & Pregnant & 34 & 1 & 8 \\
\hline Julie & 1 & 0 & White & Pregnant & 21 & 1 & 8 \\
\hline Sophie & 3 & 1 & White & Pregnant & 28 & 1 & 18 \\
\hline Susan & 1 & 0 & White & Pregnant & 31 & 1 & 15 \\
\hline Rachel & 2 & 0 & White & Pregnant & 35 & 1 & 28 \\
\hline Lisa & 3 & 1 & White & Pregnant & 34 & 1 & 16 \\
\hline Kim & 2 & 0 & White & Pregnant & 20 & 1 & 11 \\
\hline Sanaa & 3 & 2 & SE Asian & Pregnant & 32 & 1 & 22 \\
\hline Baljit & 2 & 1 & SE Asian & Pregnant & 25 & 2 & 2 \\
\hline Sabina & 4 & 3 & SE Asian & Pregnant & 23 & 2 & 1 \\
\hline Fatima & 4 & 3 & SE Asian & Pregnant & 27 & 2 & 8 \\
\hline Rehana & 3 & 2 & SE Asian & Pregnant & 38 & 1 & 2 \\
\hline Sylvia & 5 & 3 & Black African & Pregnant & 42 & 2 & 7 \\
\hline
\end{tabular}

a Pseudonyms. 
lack of personal control that they felt whilst being pregnant. They attributed this to the need to be compliant for the benefit of their own and their babies' health. This lack of control presented itself in two main ways. Firstly, women expressed frustration at losing control to a system of care which disrupted their everyday lives, and secondly, they expressed an acceptance of surrendering their control to health-care professionals and influential others.

\section{Disruption to everyday lives}

Women who have diabetes invariably have more regular hospital appointments than the straightforward maternity population. This regular attendance, although generally accepted by women, created enormous disruption to their home and work life. Women generally attempted to weigh up the advantages and disadvantages of attending clinic; for example, Heather stated:

Really I suppose the only thing is coming out of work really... So that makes me more stressful coming back into work afterwards, so the benefits of coming in can sometimes be outweighed by the negative of being away from work as well.

Fatima echoed these views by airing her frustrations at the disruption to her children's lives, as well as her own:

I would say it's more stressful because you're more in hospital. You're coming at least twice a week...it's another headache...And it's so hard to squash everything in. Like this morning I had to drop my kids at eight o'clock in school-they have breakfast club, so I'm lucky that way, so I could drop them off early to get here for nine o'clock... It's too much. And then I think, 'Oh, my God, is this all necessary?' and the waiting times are just a laugh.

Explaining the regularity of hospital appointments to women in preconception counselling sessions would enable women to plan their daily routines accordingly.

\section{Surrendering control to others}

Despite the disruption to their lives, pregnant and nonpregnant women were generally accepting of the need to surrender their control to health-care professionals in relation to childbirth decisions. For the White British women, this was influenced by their assumptions that there would be complications in their pregnancies. The language used by some women demonstrated detachment from their infant, indicative of their uncertainty that the pregnancy would result in a live healthy infant. Anne, for example, said:

...it's more miscarriage, it's more stillbirth. I mean, I know that doesn't always have to be the way but it seems to me that if you've already got problems anyway they just escalate and escalate, so I don't know, I'm frightened... you just have to wait and see if something really horrible happens to it [baby] but you just do your best to try and make sure that it doesn't.

However, handing over control created vulnerability, especially for those women who had managed their diabetes for some time:

I suppose the only thing with coming in so often, like now with the pregnancy, you know it's right for the baby and yourself but you do feel quite vulnerable as well' cause you think suddenly something that you can control is something that you can't control really. And always having to accept that other people will want to know what the blood is doing... so I've got to come in after 23 years of managing this to have someone else tell me, you know what to do with it... [Heather]

For the non-British women, it was the high level of trust in the care providers which made it easier to relinquish their control:

I want to know why and they've told me that they are using it now [metformin] but they didn't give any explanation, which I have to accept because they are the doctors and they know what is better, so I am just waiting now to look if my baby comes out. [Sylvia]

This was supported by the South East Asian women who accepted the responses of health professionals to questions posed. For example, when Baljit asked questions regarding the size of the baby and mode of birth, she was told, 'Don't even think about that yet'. She stated that this reassured her as she trusted the person providing the response.

The non-English-speaking South East Asian women's perceptions were different to those of the White British or Westernised South East Asian women. Culturally, this group of women's beliefs and family values were the greatest influence on their acceptance of childbirth decisions; for example, Sabina, when discussing diabetes care, said 'It is up to God who will decide the right way'.

Family members appeared to have a stronger influence on the South East Asian women than on the White British women. For example, Fatima told of how her mother was 'scared' that she would pass diabetes on to her infant, and stated that 'she wouldn't let me breast feed him'.

All but one of the women assumed that they would have a caesarean birth. With current national caesarean rates being as high as 67\% (Confidential Enquiry into Maternal And Child Health, 2007) for women with diabetes, their assumptions were somewhat grounded. However, disappointingly, birth method was not discussed with any of these women, leaving them to guess what would occur:

...someone's briefly mentioned that I'll probably have it a couple of weeks early. I'm surmising I'll have a caesarean then (laughs) I can't surmise anything else. Erm, but nobody has really gone into details with that. [Rachael]

The Asian women appeared more apprehensive of having a caesarean birth than the British women:

I am scared of having an operation; everything is different here than India. [Rehana]

One woman, at 30 weeks of gestation, was so worried about the outcome for her infant that she was too scared to even consider the actual birth. She said:

Is my child gonna be all right, when I give birth to it? Is it gonna have all its limbs? It's just the thought, it just makes you scared and I just think if I stay pregnant it's alright... I won't be able to see it...[Fatima]

\section{Pregnancy overshadowed by diabetes}

All pregnant women commented on their disappointment that, during their hospital visits, the over-riding focus was on diabetes management, as opposed to the fact that they were pregnant. Rather than feeling reassured by the centrality of the diabetes to 
their antenatal visits, this made some women more anxious. Sabina, for example, said:

She explained if blood sugars are not controlled, baby could be aborted. You could have a heart attack. There are chances where it could have a negative effect on me and is upsetting.

Even the non-pregnant group of women recognised how diabetes would impact on them if pregnant. For example, Joanna said:

It's like you get a label on you isn't it? And they just think, you know, they've got to focus on just that and I feel by focusing on my diabetes, this may sound really silly but by focusing on the diabetes, I feel I lose control of it because it nerves me, it frightens me then and I start panicking about it [pregnancy]...

Susan, who saw the midwife for the first time at 28 weeks of gestation, told of her relief when the fact that she was having a infant was acknowledged:

I haven't actually talked about having a baby at all really. It's all been 'How are your blood sugars? How are your thyroid levels? What's the scan telling us?' It's been quite erm... fact based and medical, you know like 'These levels are right' and there's been no...touchy-feely, soft kind of information. Whereas today she [midwife] measured my tummy with the tape measure... and she listened to the baby's heartbeat and then she was just talking about the baby and things...

Rachael attempted to balance out the need for safety with that of enjoyment:

'I've had nobody to speak to because it's just so medical which is absolutely understandable because you want your sugars to be absolutely perfect and that's the main objective. But you've gotta remember I'm having a baby and it's my first baby, I don't know what's going on with my body.

Although women generally understood the need for intensive diabetes monitoring, they demonstrated a degree of emotional anxiety which arose from the lack of personal preparation, feeling guilty for not preparing (e.g. taking folic acid) and insufficient information. Sophie's experience demonstrates this range of emotions:

last year when I lost the other one [baby], I knew that if your blood sugars were high there was higher risk of abnormalities...but I just took it with a pinch of salt...it was only after losing the baby and me asking them, 'Could this be down to my blood sugars?' and they said they don't have an answer, it could be. You know, and you think, 'Well, this could have been my fault'. You know and then you have to live with all the guilt of it then, so if the information was given to me straightaway, or as I say, beforehand... whereas this time I've thought of my blood sugars, 'I've got to get my blood sugars down!'....You know, it was a good kick up the bum.

\section{Haphazard preconception care}

Only $35 \%$ of women with diabetes attend for preconception counselling (Confidential Enquiry into Maternal And Child Health, 2007). Women in this study appeared to be more inclined to go for preconception care if they had been directly referred, for example by their general practitioner, and were having difficulty conceiving. Yana, for example, had three years of infertility and attended for preconception care due to 'pressure from outside'. This pressure came from her extended family and friends:

in our culture, once you're married, it's babies, you know and I've been married for three years now and it's all been expected...I mean it's three years...too late now...I mean, why is she not having kids?

Rehana's desire to conceive a male infant influenced her decision to ignore the medical advice not to get pregnant, despite being informed that pregnancy was a risk to herself because of her diabetes.

Only those planning a pregnancy and multigravida women who had experienced pregnancy or pregnancy loss realised the importance of preconception care. The general apathy towards preconception care was influenced by a lack of information and/or a lack of emphasis from professionals on the importance of attendance. For example, Lisa said:

When I came, we just had vague chats about it to be honest.

Sophie said:

Erm, but I didn't know things like that existed.... I didn't know anything like that, you know was available to you and I wouldn't have even of known who to ask or where to go or...I wouldn't have had a clue.

South East Asian women appeared to be less likely to know about preconception care. Even though Fatima had encountered pregnancy complications in previous pregnancies, she had not attended; she stated that she would have attended preconception care had she known that the service existed.

Those who knew about preconception care were reluctant to attend. This was either because of the inconvenience of taking time off work, having to provide an explanation for absence or not enjoying the experience on a previous occasion. Susan, for example, said:

It's such a private thing, isn't it? ...just to attend a clinic you have to tell work where you're going or friends and family where you're going...too much like hassle really sometimes if you think I've got to tell a few white lies because I don't want them to know that we're trying [to conceive] and things like that.

Rachel recalled her previous experience of attending a preconception clinic, suggesting a paternalistic health professional approach:

I found it really intimidating just because it was the way we were treated, the way that it was kind of drummed in, 'You can't get pregnant until your blood sugars right!' kind of thing and it were like, 'Yeah, fine' but who are you to kind of judge me on that. I know what you're saying from a medical side but there could be a bit more sort of compassion there. I don't think it were advertised enough... it was just like coming to a diabetic clinic but getting a little bit more told off! (laughs) to get it right. And each week that you came it was like, 'No, it's not come down enough', 'No, it's not come down enough', 'No, it's not come down enough' and you just get jaded by it and you just think 'Forget it!' You know, it's a bit off-putting.

\section{Discussion}

This small exploratory study has provided insight into the lived experience of women of reproductive age with diabetes. As with 
many qualitative studies, this study generated a wealth of important data on women's experiences; however, given that the study aimed to explore views related to a number of variables (parity, diabetes type, ethnicity and pregnancy state), the sample size was limiting. Groups were not homogenous. The South East Asian women, for example, represented a number of different cultures. Nevertheless, this is the first study to begin exploring diabetes and pregnancy within different populations. Overall themes were consistent between the different ethnic groups, but some differences were observed, stemming from cultural beliefs. To understand the complexity and influence of such beliefs, further work is required. This is of particular importance as ethnicity has a significant impact on the outcome of diabetes pregnancies, with worse outcomes for Asian women (Verheijen et al., 2005).

The strength of this work is that it offers an alternative perspective, i.e. that of the women, which should make health professionals question their approach to supporting women with diabetes. Its applicability to the health needs of a multicultural society, aided by the use of lay researchers, is also unique.

Unsurprisingly, women valued their diabetes management and understood the importance of this to their own and their babies, well-being. As suggested by others (Berg and Honkasalo, 2000), the concept of control played an integral role in the experiences of women. In the present study, this was presented negatively and positively. Women were accepting of transferring personal control to professionals when childbirth decisions had to be made, but were dissatisfied with the control lost due to disruption to their daily lives. The potential to develop complications during pregnancy was a particular influence on women's experiences. This not only resulted in a lack of contribution towards childbirth decision making but also re-inforced the medicalisation of their pregnancy. It appears that women now strive for a good outcome and a fulfilling experience of pregnancy and childbirth, regardless of pregnancy risk. However, a lack of sensitivity to women's pregnancy needs resulted in women feeling disappointed and less able to enjoy the experience. This was mainly due to the routines of care and a medicalised approach. Such an approach to care is likely to promote women's disengagement with health professionals. Getting through the pregnancy took precedence over looking forward to the birth of the infant. Furthermore, the fatalistic attitude of women towards birth mode may in fact be contributing to the caesarean section rate of women with diabetes. This is an area that warrants further investigation.

Strategies need to be developed to ensure that whilst safety is maintained, the pregnancy focus is not lost. Incorporating a social model of care alongside a medical model may result in a more positive experience whilst maintaining good clinical outcomes. Like Duncombe (2003), the present authors propose that health professionals should normalise the pregnancy experience for women, as much as possible, alongside the diabetes care. The apparent convergence of roles within multidisciplinary teams needs consideration, and is likely to be applicable to other specialist clinics within obstetrics. Although multidisciplinary diabetes teams are now commonplace and considered integral to improving clinical outcomes, individual members (i.e. midwives, obstetricians, physicians and dieticians) need to re-evaluate their own role within that team, recognising their unique contribution.

Lack of preparation for pregnancy was evident in this study. However, whilst the Confidential Enquiry into Maternal And Child Health (2005) has reported the lack of preparation in terms of glycaemic control and folic acid uptake, the present study also found that women feel ill prepared for the reality of having diabetes and being pregnant; this created emotional anxiety. Preconception care needs to be accessible and responsive to women. This is currently not the case, with only $17 \%$ of units reporting formal diabetes preconception services (Confidential Enquiry into Maternal and Child Health, 2004). Preconception services should include recognition of socio-cultural differences and be sensitive to women's desires to have an infant as well as optimising diabetes well-being. Windows of opportunity to discuss preconception care appear to be missed by health professionals, as some women would be willing to attend if they were aware of their existence and were directly referred. A coordinated approach to providing and re-inforcing the importance of preconceptual care is pivotal to uptake; this should occur on multiple levels. Preconception care should include discussions regarding what to expect when they get pregnant, as opposed to being focused solely on diabetes management. The challenge for health professionals is to provide realistic information to women whilst not deterring them from attending. Health professionals should also engage with significant family members, where appropriate.

This study has provided useful insight into issues of importance to women with diabetes of childbearing age, and could be used as a foundation for future work in this area.

\section{Conflict of Interest}

None of the authors have any known conflict of interest.

\section{Acknowledgements}

The authors wish to thank the women who participated in this study, the lay researchers (Parveen Ramzan, Safira, Patel Narmin Rokad and the diabetes specialists (Christine Bond, Pam Inniss, Sue Spellman, Lorna Wood and Gill Morrison). The study was funded by Diabetes UK.

\section{References}

Berg, M., 2005. Pregnancy and diabetes: how women handle the challenges Journal of Perinatal Education 14, 23-32.

Berg, M., Honkasalo, M.L., 2000. Pregnancy and diabetes-a hermeneutic phenomenological study of women's experiences. Journal of Psychosomatic Obstetrics and Gynaecology 21, 39-48.

Berg, M., Lundgren, I., Lindmark, G., 2003. Childbirth experience in women at risk: is it improved by a birth plan? Journal of Perinatal Education 12,1-15.

Carter, B., 2004. How do you analyse qualitative data. In: Lavender, T., Edwards, G., Alfirevic, Z. (Eds.), Demystifying Qualitative Research in Pregnancy and Childbirth. Quay Books, Salisbury, pp. 87-107.

Casson, I.F., Clarke, C.A., Howard, C.V., 1997. Outcomes of pregnancy in insulin dependent diabetic women: results of a five year population cohort study. British Medical Journal 315, 275-278.

Clifford, C., 1997. Qualitative Research Methodology in Nursing \& Healthcare Churchill Livingstone, London.

Confidential Enquiry into Maternal and Child Health, 2004. Maternity Services in 2002 for Women with Type 1 and Type 2 Diabetes, England, Wales and Northern Ireland. CEMACH, London.

Confidential Enquiry into Maternal and Child Health, 2005. Pregnancy in Women with Type 1 and Type 2 Diabetes in 2002-2003. England, Wales and Northern Ireland. CEMACH, London.

Confidential Enquiry into Maternal and Child Health, 2007. Diabetes in Pregnancy: are we Providing the Best Care? England, Wales and Northern Ireland. CEMACH, London.

Curtis, M., Abelman, S., Schulkin, J., Williams, J.L., Fassett, E.M., 2006. Do we practice what we preach? A review of actual clinical practice with regards to preconception care guidelines. Maternal Child Health Journal 10 (Suppl. 1) 53-58.

Duncombe, C., 2003. Diabetes: who is in control? Midwifery Digest 13, 473-476.

Evers, I.M., Valk, H.W.de., Visser, G.H.A., 2004. Risk of complications of pregnancy in women with type 1 diabetes: nationwide prospective study in the Netherlands. British Medical Journal (published 5 April 2004).

Gadamer, H.G., 1989. Truth and Method (J. Weinsheimer and D.G. Marshall, Trans.) Crossroad, New York.

Gibbins, J., Thomson, A.M., 2001. Women's expectations and experiences of childbirth. Midwifery 17, 302-313. 
Gupton, A., Heaman, M., Chung, L.W.K., 2001. Complicated and uncomplicated pregnancies: women's perception of risk. Journal of Obstetrics and Gynecologic Neonatal Nursing 30, 192-201.

Hadden, D.R., Alexander, A., McCance, D.R., Traub, A.I., 2001. Obstetric and diabetic care for pregnancy in diabetic women: 10 years outcome analysis, 1985-1995. Diabetic Medicine 18, 546-553.

Hanson, U., Persson, B., 1993. Outcome of pregnancies complicated By type-1 insulin-dependent diabetes in Sweden-acute pregnancy complications, neonatal-mortality and morbidity. American Journal of Perinatology 10, 330-333.

Hatmaker, D.D., Kemp, V.H., 1998. Perception of threat and subjective well-being in low risk and high-risk pregnant women. Journal of Perinatal and Neonatal Nursing 12, 1-10.

Hawthorne, G., 2005. Preconception care in diabetes. Seminars in Fetal and Neonatal Medicine 10, 325-332.

Hawthorne, G., Robson, S., Ryall, EA., Sen, D., Roberts, S.H., Platt, M.P.W., 1997. Prospective population based survey of outcome of pregnancy in diabetic women: results of the northern diabetic pregnancy audit, 1994. British Medical Journal 315, 279-281.

Heidegger, M., 1962. Being and Time (J. Macquarrie and E. Robinson, Trans.). Harper \& Row, New York.

Kapoor, N., Sankaran, S., Hyer, S., Shehata, H., 2007. Diabetes in pregnancy: a review of current evidence. Current Opinion in Obstetrics and Gynecology 19, 586-590.

Landon, M.B., Gabbe, S.G., Piana, R., Mennuti, M.T., Main, E.K., 1987. Neonatal morbidity in pregnancy complicated by diabetes-mellitus-predictive value of maternal glycemic profiles. American Journal of Obstetrics and Gynaecology $156,1089-1095$.
Lavender, T., Walkinshaw, S., Walton, I., 1999. A prospective study of women's views of factors contributing to a positive birth experience. Midwifery 15 40-46.

Macintosh, M.C., Fleming, K.M., Bailey, J.A., et al., 2006. Perinatal mortality and congenital anomalies in babies of women with type 1 or type 2 diabetes in England, Wales, and Northern Ireland: population based study. British Medical Journal 333, 177.

Mapp, T., 2008. Understanding phenomonology: the lived experience. British Journal of Midwifery 16, 308-311.

McAuliffe, F.H., Foley, M., Firth, R., Drury, I., Stronge, J.M., 1999. Outcome of diabetic pregnancy with spontaneous labour after 38 weeks. Irish Journal of Medical Science 168, 160-163.

Nielsen, G.L., Nielsen, P.H., 1993. Outcome of 328 pregnancies in 205 women with insulin-dependent diabetes-mellitus in the county of Northern Jutland from 1976 to 1990. European Journal of Obstetrics Gynecology and Reproductive Biology 50, 33-38.

Platt, M.J., Stanisstreet, M., Casson, I.F., 2002. St Vincent's declaration 10 years on: outcomes of diabetic pregnancies. Diabetic Medicine 19, 216-220.

Van Manen, M., 2002. Phenomenology on-line. 〈http://www.phenomenologyonline. com $>$.

Verheijen, E.C.J., Critchley, J.A., Whitelaw, D.C., Tuffnell, D.J., 2005. Outcomes of pregnancies in women with pre-existing type 1 or type 2 diabetes, in an ethnically mixed population. British Journal of Obstetrics and Gynaecology 112, 1500-1503.

Williams, G., Pickup, J.C., 2004. Handbook of Diabetes, 3rd ed. Blackwell Science Ltd., Malden, MA.

Workshop Report, 1990. Diabetes care and research in Europe: the Saint Vincent declaration. Diabetic Medicine 7, 360. 